\title{
Vasoconstrictive effects of levobupivacaine on the basilar artery in the rabbit
}

Julide Ergil ${ }^{1}$, Hayri Kertmen², Murat Sayın ${ }^{1}$, Bora Gürer², Erdal Reşit Yılmaz², Derya Özkan¹, Ata Türker Arıkök ${ }^{3}$, Mehmet Ali Kanat ${ }^{4}$, Zeki Şekerci ${ }^{1}$

\author{
${ }^{1}$ Anesthesiology Department, Diskapi Yildirim Beyazit Education and Research \\ Hospital, Ministry of Health, Ankara, Turkey \\ ${ }^{2}$ Neurosurgery Department, Diskapi Yildirim Beyazit Education and Research Hospital, \\ Ministry of Health, Ankara, Turkey \\ ${ }^{3}$ Department of Pathology, Diskapi Yildirim Beyazit Education and Research Hospital, \\ Ministry of Health, Ankara, Turkey \\ ${ }^{4}$ National Public Health Agency, Ministry of Health, Ankara, Turkey
}

Submitted: 20 May 2013

Accepted: 4 August 2013

Arch Med Sci 2015; 11, 3: 654-659

DOI: $10.5114 /$ aoms.2015.52372

Copyright $\odot 2015$ Termedia \& Banach

\section{Abstract}

Introduction: Spinal anesthesia is a widely used technique of the modern practice of anesthesia. Spinal cord ischemia is a rare but catastrophic complication of spinal anesthesia which may be caused by a direct vasoconstrictive effect of the local anesthetic. Although the vasoconstrictive effects of levobupivacaine have been widely studied, the vasoconstrictive effects of this drug on the intradural arteries have never been studied. The aim of this study is to evaluate whether levobupivacaine has vasoconstrictive effects on the basilar artery in rabbits.

Material and methods: Thirty male New Zealand white rabbits were divided randomly into three groups of ten rabbits each: group 1 (control); group 2 (0.125\% levobupivacaine); group 3 (0.25\% levobupivacaine). The cisterna magna was punctured as described below, then $1 \mathrm{ml}$ of saline or $0.125 \%$ or $0.25 \%$ levobupivacaine was injected into the cisterna magna in $10 \mathrm{~min}$ by an infusion pump in groups 1, 2 and 3 respectively. All animals were euthanized by perfusion-fixation $30 \mathrm{~min}$ after the procedure. The luminal area and the size of the cross-sectional area for each basilar artery were measured.

Results: Both $0.125 \%$ and $0.25 \%$ levobupivacaine infusion caused significant vasoconstriction. Vasoconstriction was more significant for the $0.125 \%$ concentration.

Conclusions: The results of this study indicated that both $0.125 \%$ and $0.25 \%$ concentrations of levobupivacaine caused significant vasoconstriction of the basilar artery when administered into the subarachnoid space. This may constitute proof that subarachnoid administration of levobupivacaine may diminish the spinal cord blood flow, causing ischemia.

Key words: basilar artery, levobupivacaine, subarachnoid, vasoconstriction.

\section{Introduction}

Spinal anesthesia is one of the fundamental techniques of the modern practice of anesthesia and is proven to be a successful, predictable and low-complication application [1]. Spinal cord injury is a rare but catastrophic complication of spinal anesthesia $[1,2]$. Ischemia is one of the many mechanisms assumed for spinal cord injury such as epidur-

\author{
Corresponding author: \\ Bora Gürer MD \\ Neurosurgery Department \\ Diskapi Yildirim \\ Beyazit Education \\ and Research Hospital \\ Ministry of Health \\ 06110, Altındağ \\ Ankara/Türkiye \\ Phone: +90 5063164201 \\ Fax: +90 3123186690 \\ E-mail: boragurer@gmail.com
}


al hematoma, cauda equina syndrome, epidural abscess, trauma and chemical contamination of local anesthetic solutions [1, 2].

Levobupivacaine is a relatively newly developed long-acting amide-type local anesthetic with a clinical profile similar to bupivacaine with a greater margin of safety and reduced systemic toxicity $[3,4]$. Levobupivacaine in $0.25 \%$ or lower concentration is claimed to have vasoconstrictive activity over rat aorta [3, 5-7], blood vessels of rat sciatic nerve [8], peripheral vessels of the human skin $[9,10]$, and in patients undergoing tonsillectomy [11] and nasal surgery [12].

Although vasoconstrictive effects of levobupivacaine have been widely studied, the vasoconstrictive effects of this drug on the intradural arteries have never been studied. The aim of this study is to evaluate whether levobupivacaine has vasoconstrictive effects on the basilar artery in rabbits.

\section{Material and methods}

\section{Experimental groups}

Animals' care and all experiments were in concordance with the European Communities Council Directive of November 24, 1986 (86/609/EEC) on the protection of animals for experimental use. All experimental procedures used in this investigation were reviewed and approved by the ethical committee of Ankara Education and Research Hospital. Thirty male New Zealand white rabbits weighing 2900-3400 g were divided randomly into three groups of ten rabbits each:

Group 1: Control group $(n=10)$; a sham surgery group. In this group, after induction of anesthesia, the cisterna magna was punctured as described below and $1 \mathrm{ml}$ of physiological saline $(0.9 \% \mathrm{NaCl})$ was injected into the cisterna magna in 10 min by infusion pump after removal of the same amount of cerebrospinal fluid (CSF).

Group 2: Low-dose group $(n=10)$; the cisterna magna was punctured as described below and $1 \mathrm{ml}$ of $0.125 \%$ levobupivacaine (Chirocaine, Abbott Turkiye, Turkey) was injected into the cisterna magna in 10 min by an infusion pump (Perfusor Space Infusion System, B. Braun Melsungen AG, Germany) after removal of the same amount of CSF.

Group 3: High-dose group $(n=10)$; the cisterna magna was punctured as described below and
$1 \mathrm{ml}$ of $0.25 \%$ levobupivacaine (Chirocaine, Abbott Turkiye, Turkey) was injected into the cisterna magna in 10 min by an infusion pump (Perfusor Space Infusion System, B. Braun Melsungen AG, Germany) after removal of the same amount of CSF.

\section{Anesthesia and surgical procedure}

The animals were kept at optimal $\left(18-21^{\circ} \mathrm{C}\right)$ room temperature and fed with standard diet where a 12-h light-dark cycle was implemented. Free access to food and water was allowed. The animals were anesthetized by intramuscular administration of $70 \mathrm{mg} / \mathrm{kg}$ ketamine (Ketalar, Parke Davis Eczacıbaşı, Turkey) and $5 \mathrm{mg} / \mathrm{kg}$ xylazine (Rompun, Bayer, Turkey) combination. The trachea was intubated with a $3.0 \mathrm{~mm}$ cuffed tube, and mechanical ventilation was accomplished with a Servo $900 \mathrm{C}$ ventilator (Siemens, Erlangen, Germany) to maintain normocarbia at a fraction of inspired oxygen of 0.3. All the animals were kept intubated until the perfusion-fixation was performed. Arterial blood samples for $\mathrm{PO}_{2}$ and $\mathrm{PCO}_{2}$ were taken from each animal from the catheterized ear arteries for blood gas analysis during the procedures, and only those animals with $\mathrm{PO}_{2}$ greater than $70 \mathrm{~mm} \mathrm{Hg}$ and $\mathrm{PCO}_{2}$ lesser than $40 \mathrm{~mm} \mathrm{Hg}$ were included in the study. Heart rate and arterial blood pressure were measured using an ear arterial catheter. Physiological parameters of the experimental groups are summarized in Table I. Core body temperature was monitored rectally and maintained at $37 \pm 0.5^{\circ} \mathrm{C}$ with a heater.

\section{Drug infusion}

The head of the rabbit was extended in the prone position. A midline nuchal incision was made, and dermal and subdermal tissues, fascia and paravertebral muscles were dissected to expose the atlanto-occipital membrane. A 25-gauge needle was inserted through the dura mater and the arachnoid membrane into the cisterna magna; $1 \mathrm{ml} / \mathrm{kg}$ of CSF was withdrawn and an equal volume of drug was injected into the cisterna magna within 10 min with an infusion pump (Perfusor Space Infusion System, B. Braun Melsungen AG, Germany). The animals were then placed in a headdown position at $30^{\circ}$ for $30 \mathrm{~min}$ to hold the drug in the basal cisterns.

Table I. Physiological parameters of the experimental groups

\begin{tabular}{|lcccccc|}
\hline Group & $n$ & $\mathrm{pH}$ & $\mathrm{PO}_{2}$ & $\mathrm{PCO}_{2}$ & $\mathrm{MABP}$ & $\mathrm{HR}$ \\
\hline Control & 10 & $7.45 \pm 0.01$ & $92 \pm 3.0$ & $34.9 \pm 1.0$ & $98 \pm 2.4$ & $170 \pm 4.5$ \\
\hline Low-dose & 10 & $7.46 \pm 0.02$ & $94 \pm 2.4$ & $34.5 \pm 1.1$ & $96 \pm 3.5$ & $171 \pm 4.9$ \\
\hline High-dose & 10 & $7.44 \pm 0.01$ & $94 \pm 2.1$ & $35.5 \pm 0.9$ & $97 \pm 2.0$ & $168 \pm 3.4$ \\
\hline
\end{tabular}

Data are expressed as mean $\pm S D$. None of the values were statistically significant between the groups $(p>0.05)$. MABP - mean arterial blood pressure $(\mathrm{mm} \mathrm{Hg}), \mathrm{HR}$ - heart rate (beats per minute). 


\section{Perfusion-fixation}

All animals were euthanized by perfusion-fixation $30 \mathrm{~min}$ after completion of the injection. The anesthesia was continued for all the animals as described above. All the animals were monitored for blood pressure and blood gas analysis. When satisfactory respiratory parameters were obtained, a thoracotomy was performed, the left ventricle cannulated, the right atrium opened widely and the descending thoracic aorta clamped. After perfusion with $300 \mathrm{ml}$ of physiological saline, a fixative was perfused (10\% formaldehyde, $200 \mathrm{ml}$ ). Perfusion was performed at a standard height of $100 \mathrm{~cm}$ from the chest. The brains were removed and stored in formaldehyde solution at $4^{\circ} \mathrm{C}$ overnight.

\section{Histological morphometric analysis of the basilar artery}

Each brainstem specimen was embedded in paraffin. The entire basilar artery was sectioned into three segments at $3 \mathrm{~mm}$ in length (Figure 1), and stained with hematoxylin-eosin $(H+E)$. The morphometric measurements on all three segments of the basilar artery were performed using BAB-Bs200ProP Image Processing and Analysis System (Ankara, Turkey). The luminal area was calculated as the area contained within the boundaries of the internal elastic lamina (Figure $2 \mathrm{~A}$ ). The size of cross-sectional area for each basilar artery was obtained by averaging these measurements. The mean \pm SD value obtained from each

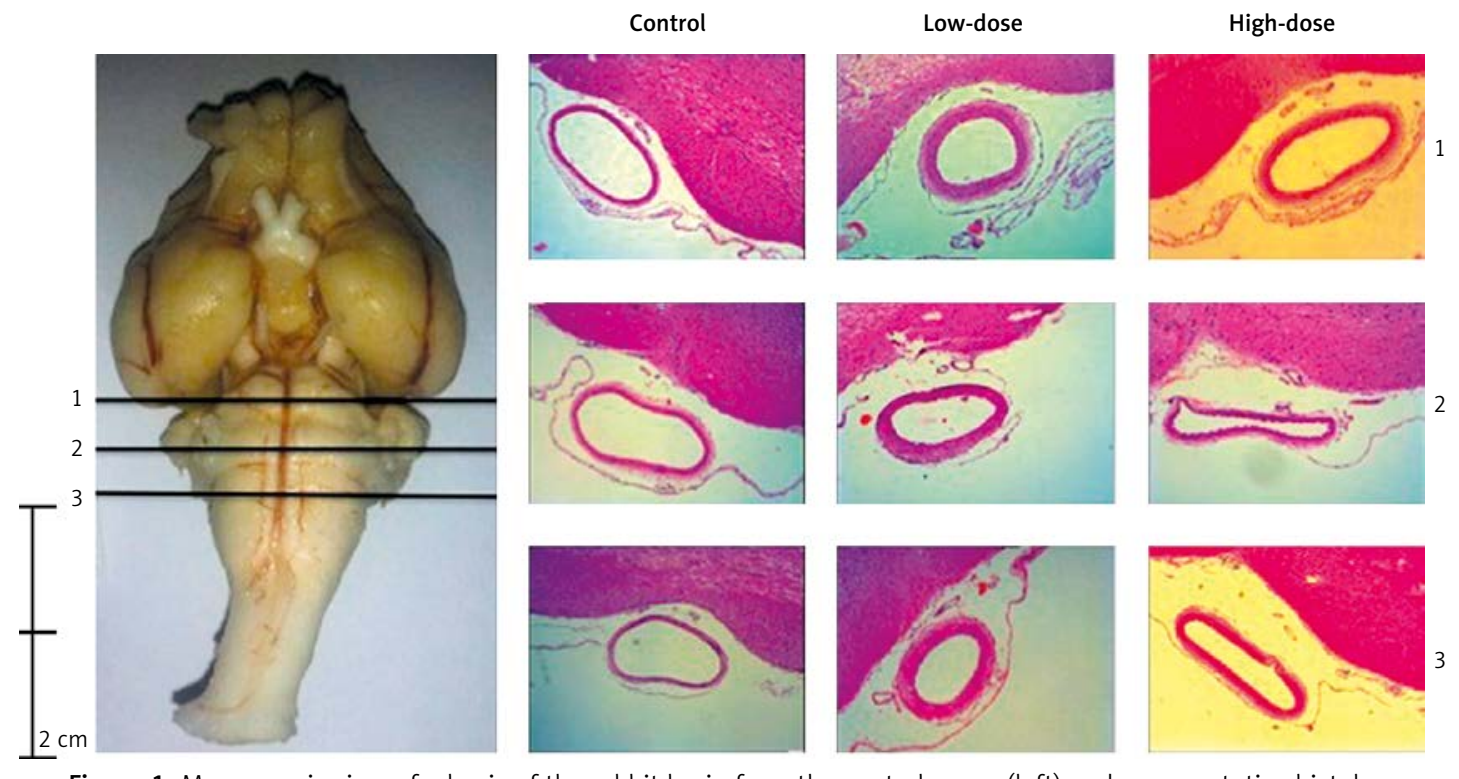

Figure 1. Macroscopic view of a basis of the rabbit brain from the control group (left) and representative histological cross-sections of the basilar artery $(\mathrm{H}+\mathrm{E} ; 40 \times$ obj.) corresponding to all groups (right)
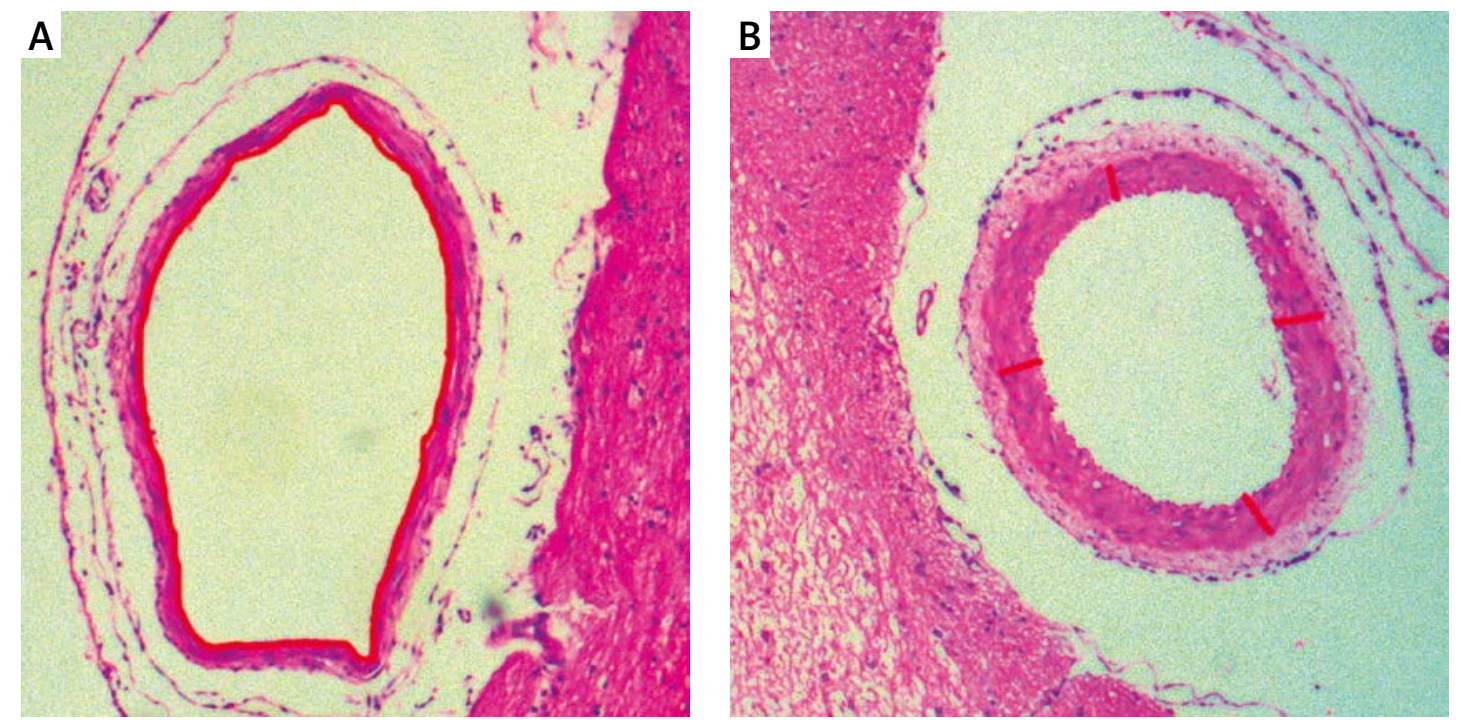

Figure 2. Demonstration of the calculation of the cross-sectional area (A) and the wall thickness (B) of the basilar artery 
Table II. Intra- and inter-observer agreement limits

\begin{tabular}{|lcc|}
\hline Measurements & $\begin{array}{c}\text { Area } \\
\text { ICC }(95 \% \mathrm{Cl})\end{array}$ & $\begin{array}{c}\text { Wall thickness } \\
\text { ICC }(95 \% \mathrm{Cl})\end{array}$ \\
\hline $\begin{array}{l}\text { Intra-observer agreement: } \\
1^{\text {st }} \text { Observer }\end{array}$ & $0.995(0.990-0.998)$ & $0.996(0.993-0.998)$ \\
\hline $2^{\text {nd }}$ Observer & $0.999(0.998-0.999)$ & $0.998(0.996-0.999)$ \\
\hline \begin{tabular}{l} 
Inter-observer agreement: \\
\hline $1^{\text {st }}$ Measurement
\end{tabular} & $0.987(0.974-0.994)$ & $0.986(0.971-0.993)$ \\
\hline $2^{\text {nd }}$ Measurement & $0.987(0.973-0.994)$ & $0.980(0.958-0.990)$ \\
\hline
\end{tabular}

ICC - Intra-class correlation coefficient, Cl - confidence interval.

artery was used as the final value for a particular vessel.

The wall thickness between the lumen and the external border of the muscle layer was measured at four quadrants of each segment of the basilar artery (Figure 2 B). If an undulating luminal border was encountered, an extra measurement was taken from the internal elastic membrane to the external border of the muscle layer. The vessel wall thickness for each basilar artery segment was obtained by averaging these measurements. The mean \pm SD value obtained from each artery was used as the final value for a particular vessel.

All measurements were repeated three times for each artery in a blind fashion by two pathologists, and the conclusive values were obtained by averaging these measurements. Inter-observer reliability levels for area and wall thickness are given in Table II.

\section{Statistical analysis}

A pilot study was conducted with 9 animals for 3 groups in order to calculate the number of animals to achieve $95 \%$ power with $5 \%$ error. The software $G^{\star}$ Power 3.0 was used to perform power analysis. The mean basilar artery cross-sectional area was used to calculate "effect size $\rho$ ". The number of animals necessary for the study, with effect size $f=0.777, \alpha$-error $=0.05$ and power $(1-\beta)$ $=0.95$, was calculated as 30 .

Data analysis was performed by using SPSS for Windows, version 11.5 (SPSS Inc., Chicago, IL, United States). Intra-class correlation coefficient (ICC) and 95\% Cl for area and wall thickness were calculated for determining both inter- and intra-observer reliability levels. Whether the distributions of continuous variables were normal was determined using the Shapiro-Wilk test. Levene's test was used to evaluate homogeneity of variances. Data are shown as mean \pm standard deviation. The mean differences among groups were analyzed by one-way ANOVA following the post hoc Tukey test. A $p$ value less than 0.05 was considered statistically significant.

\section{Results}

The mean basilar artery cross-sectional area in the control group was $310422.3 \pm 54199.3 \mu \mathrm{m}^{2}$. In the low-dose and the high dose groups the mean basilar artery cross-sectional areas were decreased to $144054.4 \pm 28253.9 \mu^{2}$ and $244173.0 \pm 48933.2$ $\mu \mathrm{m}^{2}$ respectively. When compared with the control group the decrease in the mean basilar artery cross-sectional area was statistically significant in both low-dose and high-dose groups $(p<0.001$ and $p=0.008$ respectively). When the low-dose and the high-dose groups were compared to each other, the difference was also statistically significant $(p<0.001)$ (Figure 3). The mean basilar artery crosssectional area values are shown in Table III.

The mean value of the basilar artery wall thickness was $25.4 \pm 3.4 \mu \mathrm{m}$ in the control group. In the low-dose and the high-dose groups the mean

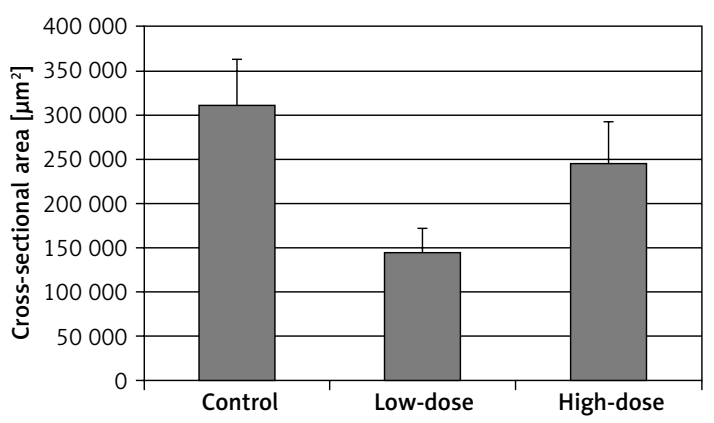

Figure 3. Mean basilar artery cross-sectional areas of the study groups

Values are expressed as mean $\pm S D$.

Table III. Cross-sectional area measurements for groups

\begin{tabular}{|lc|}
\hline Groups & Cross-sectional area \\
\hline Control & $310422.3 \pm 54199.3^{\mathrm{a}, \mathrm{b}}$ \\
\hline Low-dose & $144054.4 \pm 28253.9^{\mathrm{a}, \mathrm{c}}$ \\
\hline High-dose & $244173.0 \pm 48933.2^{\mathrm{b}, \mathrm{c}}$ \\
\hline Value of $p^{\ddagger}$ & $<0.001$ \\
\hline
\end{tabular}

${ }^{\ddagger}$ One-way ANOVA, ${ }^{a}$ Control vs. low-dose $(p<0.001)$, ${ }^{b}$ control vs. high-dose $(p=0.008)$, clow-dose vs. high-dose $(p<0.001)$. 


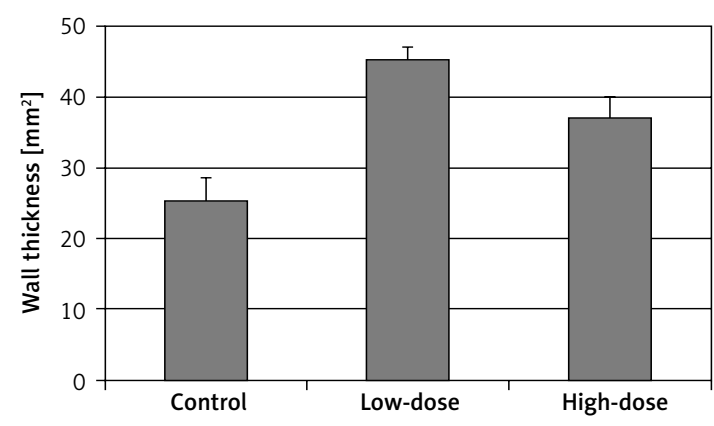

Figure 4. Mean basilar artery wall thicknesses of the study groups

Values are expressed as mean $\pm S D$.

Table IV. Wall thickness measurements for groups

\begin{tabular}{|lc|}
\hline Groups & Wall thickness \\
\hline Control & $25.4 \pm 3.4^{\mathrm{a}, \mathrm{b}}$ \\
\hline Low-dose & $45.2 \pm 2.3^{\mathrm{a}, \mathrm{c}}$ \\
\hline High-dose & $37.0 \pm 3.2^{\mathrm{b}, \mathrm{c}}$ \\
\hline Value of $p^{\ddagger}$ & $<0.001$ \\
\hline
\end{tabular}

${ }^{\ddagger}$ One-way ANOVA, ${ }^{a}$ Control vs. low-dose $(p<0.001),{ }^{b}$ control vs. high-dose $(p<0.001)$, clow-dose vs. high-dose $(p<0.001)$.

value of the basilar artery wall thicknesses was $45.2 \pm 2.3 \mu \mathrm{m}$ and $37.0 \pm 3.2 \mu \mathrm{m}$ respectively. When compared with the control group, the increase in the mean basilar artery wall thickness was statistically significant in both low-dose and high-dose groups ( $p<0.001$ for both). When the low-dose and the high-dose groups were compared to each other, the difference was also statistically significant $(p<0.001)$ (Figure 4). The arterial wall thickness values are shown in Table IV.

These results show that both low-dose and high-dose infusions caused significant vasoconstriction; also vasoconstriction was more significant in the low-dose group.

\section{Discussion}

Spinal anesthesia is one of the most common interventions used in the daily practice of anesthesia. Severe neurological deficits following subarachnoid administration of local anesthetic are rare, but when they happen they have catastrophic consequences [2]. The incidence of permanent neurological injury after spinal anesthesia was reported as 1 : 20 000-30 $000[1,13]$. The most benign neurological complication of spinal anesthesia is aseptic meningitis. Furthermore, more severe complications such as cauda equina syndrome, adhesive arachnoiditis, epidural abscess, epidural hematoma, direct injury to the spinal cord, and chemical contamination of the local anesthetic have been reported $[1,2,14]$.

Spinal cord ischemia following spinal anesthesia is one of the suspected reasons of the post-an- esthesia neurological deficit [2]. It is well known that obstruction of the blood flow to the spinal cord causes spinal cord infarct leading to paralysis or paresis $[2,15,16]$. The spinal cord is very sensitive to ischemia; only 1 to 20 min of obstruction of the blood flow may cause paresis [16]. It has been suggested that during surgery under spinal anesthesia prolonged arterial hypotension may be the cause of the spinal cord ischemia [17, 18]. Nevertheless, other factors are possibly involved, as in spinal anesthesia controlled hypotension is produced without causing neurological deficit. Vasoconstriction caused by the direct effect of the local anesthetic on the subarachnoid vessels has been postulated to cause spinal cord ischemia [1, 2].

It is well documented that amino amide local anesthetics cause vasoconstriction at low doses and vasodilatation at high doses [3, 5-7, 19-22]. Levobupivacaine (an S-isomer of bupivacaine) is a recently developed amino amide local anesthetic that belongs to the $n$-alkyl-substituted pipecholyl xylidine family [4]. With its unique structure, lipid solubility and potency are increased [4, 23]. Vasoconstrictive potency of levobupivacaine has been widely studied [3, 5-12]. Direct administration of levobupivacaine caused significant vasoconstriction in rat aorta [3, 5-7], microvessels of the rat sciatic nerve [8], peripheral human skin [9, 10] and also in tonsillectomy and nasal areas [11, 12]. Levobupivacaine is clinically used at concentrations of $0.25 \%$ to $0.75 \%$ for spinal anesthesia $[7,24]$. Levobupivacaine has been shown to exert vasoconstrictive effects in concentrations $\leq 0.25 \%$ $[10,12]$. Newton et al. $[9,10]$ studied the human skin blood flow changes with different concentrations of levobupivacaine and bupivacaine and demonstrated biphasic effect on skin microvessels. Both anesthetics caused vasodilatation at higher doses and vasoconstriction at lower doses.

Levobupivacaine was shown to increase intracellular calcium concentration, resulting in vasoconstriction in isolated vessels [5]. A change in the concentration of the cytosolic free calcium is responsible for the calcium-dependant mechanism of vascular smooth muscle constriction [25]. Calcium is mobilized from the sarcoplasmic reticulum to increase the cytosolic free calcium concentration, which stimulates the binding of calcium to calmodulin, leading to vasoconstriction [25]. Levobupivacaine-induced vasoconstriction is also mediated by lipoxygenase pathways, which seems to facilitate calcium influx via voltage-operated calcium channels, and this mechanism is assumed to be the main mechanism of the vasoconstriction [3]. Also, lipid solubility of the local anesthetic is correlated with the vasoconstrictive effect, and levobupivacaine is a highly lipid-soluble local anesthetic [6]. Eventually, it has been 
widely accepted that levobupivacaine has a potent vasoconstrictive effect [3,5-10]. Newton et al. [10] showed that levobupivacaine caused net vasoconstriction at $20 \mathrm{~min}$ from baseline. So, in the present study, we decided on a time to scarification of 30 min after the start of levobupivacaine administration.

As mentioned, the vasoconstrictive effects of levobupivacaine have been widely studied in rat aorta, sciatic nerve and human skin [3, 5-10]. No such study was performed to analyze the vasoconstrictive effect of levobupivacaine on the subarachnoid vessels. In this study, we evaluated the vasoconstrictive effect of $0.125 \%$ and $0.25 \%$ concentrations of levobupivacaine. Both concentrations caused vasoconstriction of the basilar artery when administered into the subarachnoid space via the cisterna magna. Furthermore, the lower concentration $(0.125 \%)$ caused more significant vasoconstriction when compared to the higher concentration (0.25\%).

However, this study has some limitations. The number of rabbits in each group could be increased. Different dose- and time-dependent results may be investigated. Also, another limitation of this study is the lack of functional outcome measures.

The results of this study showed that both $0.125 \%$ and $0.25 \%$ concentrations of levobupivacaine caused significant vasoconstriction of the basilar artery when administered into the subarachnoid space. This may constitute proof that subarachnoid administration of levobupivacaine may diminish the spinal cord blood flow, causing ischemia.

\section{Conflict of interest}

The authors declare no conflict of interest.

\section{References}

1. Mordecai MM, Brull SJ. Spinal anesthesia. Curr Opin Anaesthesiol 2005; 18: 527-33.

2. Kane RE. Neurologic deficits following epidural or spinal anesthesia. Anesth Analg 1981; 60: 150-61.

3. Choi YS, Jeong YS, Ok SH, et al. The direct effect of levobupivacaine in isolated rat aorta involves lipoxygenase pathway activation and endothelial nitric oxide release. Anesth Analg 2010; 110: 341-9.

4. Casati A, Putzu M. Bupivacaine, levobupivacaine and ropivacaine: are they clinically different? Best Pract Res Clin Anaesthesiol 2005; 19: 247-68.

5. Baik JS, Sohn JT, Ok SH, et al. Levobupivacaine-induced contraction of isolated rat aorta is calcium dependent. Can J Physiol Pharmacol 2011; 89: 467-76.

6. Sung HJ, OK SH, Sohn JY, et al. Vasoconstriction potency induced by aminoamide local anesthetics correlates with lipid solubility. J Biomed Biotechnol 2012; 2012: 170958.

7. Shim HS, Ok SH, Lee SH, Kwon SC, Sohn JT. Protein kinases participate in the contraction in response to levobupivacaine in the rat aorta. Eur J Pharmacol 2012; 677: 131-7.

8. Bouaziz H, lohom G, Estèbe JP, Campana WM, Myers RR. Effects of levobupivacaine and ropivacaine on rat sciatic nerve blood flow. Br J Anaesth 2005; 95: 696-700.

9. Newton DJ, McLeod GA, Khan F, Belch JJ. Vasoactive characteristics of bupivacaine and levobupivacaine with and without adjuvant epinephrine in peripheral human skin. Br J Anaesth 2005; 94: 662-7.

10. Newton DJ, McLeod GA, Khan F, Belch JJ. The effect of adjuvant epinephrine concentration on the vasoactivity of the local anesthetics bupivacaine and levobupivacaine in human skin. Reg Anesth Pain Med 2004; 29: 307-11.

11. Ergil J, Akkaya T, Gozaydin O, et al. Vasoconstrictive and analgesic efficacy of locally infiltrated levobupivacaine in tonsillectomy patients. Int J Pediatr Otorhinolaryngol 2012; 76: 1429-33.

12. Demiraran Y, Ozturk O, Guclu E, Iskender A, Ergin MH, Tokmak A. Vasoconstriction and analgesic efficacy of locally infiltrated levobupivacaine for nasal surgery. Anesth Analg 2008; 106: 1008-11.

13. Moen V, Dahlgren N, Irestedt L. Severe neurological complications after central neuraxial blockades in Sweden 1990-1999. Anesthesiology 2004; 101: 950-9.

14. Reisner LS, Hochman BN, Plumer MH. Persistent neurologic deficit and adhesive arachnoiditis following intrathecal 2-chloroprocaine injection. Anesth Analg 1980; 59: 452-4.

15. Yilmaz ER, Kertmen H, Dolgun $H$, et al. Effects of darbepoetin-alpha in spinal cord ischemia-reperfusion injury in the rabbit. Acta Neurochir (Wien) 2012; 154: 1037-43.

16. Heymans C. Survival and revival of nervous tissues after arrest of circulation. Physiol Rev 1950; 30: 375-92.

17. Bromage PR. 'Paraplegia following epidural analgesia': a misnomer. Anaesthesia 1976; 31: 947-9.

18. Editorial: Spinal stroke. Lancet 1974; 2: 1299-300.

19. Löfström JB. 1991 Labat Lecture. The effect of local anesthetics on the peripheral vasculature. Reg Anesth 1992; 17: 1-11.

20. Ok SH, Sohn JT, Baik JS, et al. Lipid emulsion reverses levobupivacaine-induced responses in isolated rat aortic vessels. Anesthesiology 2011; 114: 293-301.

21. Newton DJ, Burke D, Khan F, et al. Skin blood flow changes in response to intradermal injection of bupivacaine and levobupivacaine, assessed by laser Doppler imaging. Reg Anesth Pain Med 2000; 25: 626-31.

22. Willatts DG, Reynolds F. Comparison of the vasoactivity of amide and ester local anaesthetics. An intradermal study. Br J Anaesth 1985; 57: 1006-11.

23. Heavner JE. Local anesthetics. Curr Opin Anaesthesiol 2007; 20: 336-42.

24. Costello TG, Cormack JR, Mather LE, LaFerlita B, Murphy MA, Harris K. Plasma levobupivacaine concentrations following scalp block in patients undergoing awake craniotomy. Br J Anaesth 2005; 94: 848-51.

25. Akata T. General anesthetics and vascular smooth muscle: direct actions of general anesthetics on cellular mechanisms regulating vascular tone. Anesthesiology 2007; 106: 365-91. 